THE JOURNAL OF PHILOSOPHICAL ECONOMICS:

REFLECTIONS ON ECONOMIC AND SOCIAL ISSUES

Volume XIV Issues 1-2

Spring-Autumn 2021

ISSN: $1843-2298$

EISSN: $1844-8208$

Publication date:

20 November 2021

Paper format: $16.5 \times 23.5 \mathrm{~cm}$

Copyright note:

Authors retain unrestricted copyright and all publishing rights in compliance with the Creative Commons license CC BY-NC-SA.
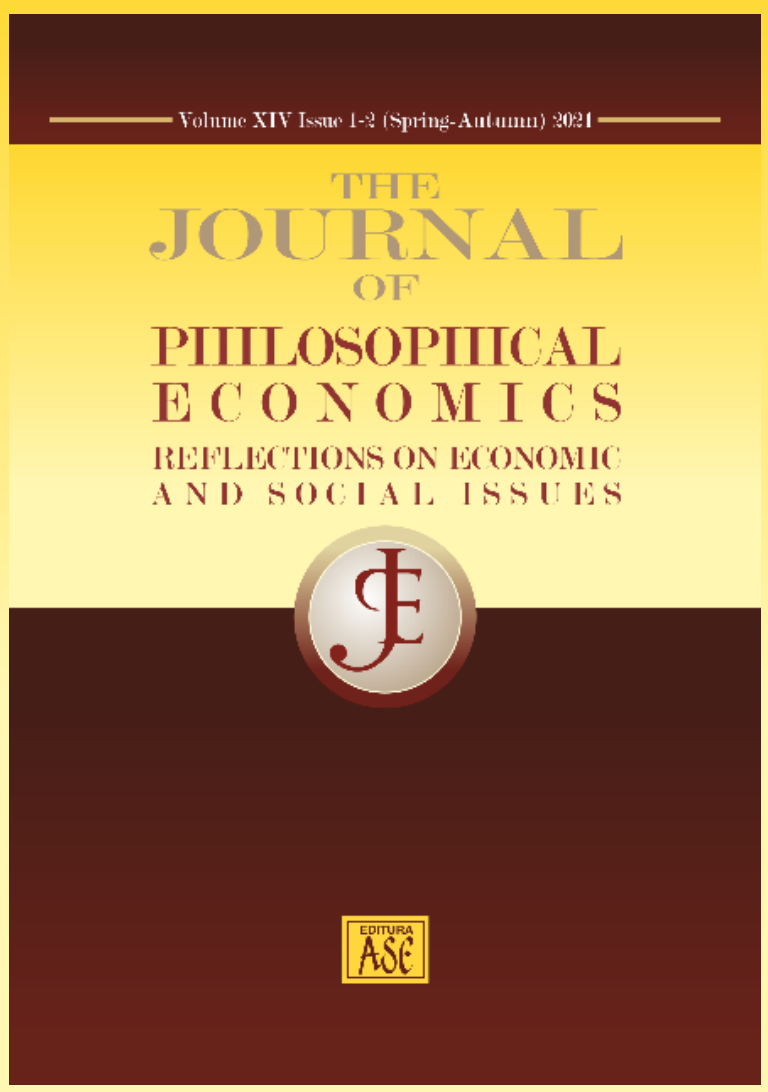

\title{
The apodictic method and the dialogue between theology and science (I)
}

Fr. Petre Comşa

Costea Munteanu 


\title{
The apodictic method and the dialogue between theology and science (I)
}

\author{
Fr. Petre Comşa \\ Costea Munteanu
}

\begin{abstract}
Many today's scientists think that religion can never come to terms with science. In sharp contrast to the widespread opinion, the authors of this paper consider that historically scientific reasoning and religious belief joined hands in their effort to investigate and understand reality. In fact, the current divorce between science and religion is nothing else than the final outcome of a gradual long-term, and deliberately assumed process of science secularization of science. However, especially during the last decades, we have all been equally confronted with the advance of a new concern over the fact that contemporary scientists have been approaching an area of investigation that had been usually addressed by the theological thought. This recent development has generated an emerging new field of investigation of Science and Religion within modern scientific epistemology.

Against this background, the purpose of this paper is three-fold: firstly, to briefly emphasize that one of the defining dimensions of the dialogue between science and religion is given by the discontinuity, in which, the knowledge acquired through scientific reasoning is placed in relation to the divinely revealed knowledge; secondly, to argue that another defining dimension of the dialogue consists in the hierarchical harmony mediating the encounter between the two, thus transgressing the discontinuity and making the dialogue between theology and science possible and viable; and thirdly, to advocate the idea that the apodictic method (based on antinomic logic) can successfully structure such a dialogue.
\end{abstract}

Keywords: discontinuity relationship; apodictic method; antinomic logic; patristic teaching; economic science

Received: 13 October 2020 
Comşa Fr. Petre, Munteanu Costea (2020), The apodictic method and the dialogue between theology and science (I), The Journal of Philosophical Economics: Reflections on Economic and Social Issues, XIV (1-2), 136-176

\section{Introduction}

There is among philosophers of science, who have studied systematically and with a particular attention the methodological status of the dialogue between science and theology, a widespread opinion that the two fields of knowledge operate with distinct methods, based on specific key concepts (experiment, model, theory, paradigm - for the scientific method; revelation, dogma, faith, prayer - for the theological method).

However, it must be clarified immediately: well-known researchers in the field (such as John Haught; Jean Staune; Alexei Nesteruk; Basarab Nicolescu; John Breck; Bruno Guideroni; or Mircea Malița) consider that this distinct and specific character of the methodological status that each of the two paths of knowledge claims are not in opposition and conflict but coexist in cooperation and convergence. In other words, science and theology do not reject but approach each other. More precisely, being in a relationship of continuity, they attract each other, assume each other.

According to one of the well-known researchers in the field, it is about a continuity of an epistemological nature: 'Science and theology can complement each other appropriately (...) If science deals with the description of the nature of the world and how it works, theology offers the interpretation of this information in the light of divine revelation' (emphasis added) (Breck 2006).

And, an ontological continuity, according to another renowned researcher in the field: '.. the essence and objective of establishing a relationship between science and theology is the connection of two different types of experience in the same human subjectivity' (emphasis added) (Nesteruk 2009, p. 75).

As far as we are concerned, we consider that the problem needs to be treated in a more nuanced way, especially when we talk specifically about the dialogue between Orthodox theology and science: as the Orthodox theology meets science taking the appearance of a gnoseological status, which is placed in a discontinuity accomplished-by a hierarchical-harmony with science, and not in the appearance of continuity (be it epistemological or ontological) or that of equality. 
Comşa Fr. Petre, Munteanu Costea (2020), The apodictic method and the dialogue between theology and science (I), The Journal of Philosophical Economics: Reflections on Economic and Social Issues, XIV (1-2), 136-176

This is what we shall discuss in the following sections. The paper is divided into two parts: the first part tackles the problem of truth in theology and science with a particular focus on the antinomic logic, while the second part aims to illustrate how the apodictic method (based on antinomic logic) effectively implements together-workingness between the scientific analysis and theological teaching by being applied to economic science using the theory of rational behaviour in relation with the issue of wealth and poverty.

\section{Discontinuity and hierarchy in the dialogue between Orthodox theology and science}

The discontinuity between 'autonomous' knowledge and 'moved-by-the-Spirit' knowledge

Speaking of the revealed divine knowledge, the Holy Apostle Paul says that his speech and preaching is not with enticing words of man's wisdom, but in demonstration of the Spirit and of power [1 Corinthians 2, 4], while St. Gregory Palamas comes and reinforces the apostle's confession, saying that 'not by persuasive words of human wisdom but by the divine do we seek the divine, by the power of the speakers-of-God, the one by the Spirit-moved' (Palamas 2013, p. 165). And St. Gregory also shows: 'We do not consider the knowledge found through reasoning and syllogisms [to be] a true opinion, but that demonstrated by facts and life, which is not only true, but also certain and unshakable [by logical arguments]', then strengthening his testimony of the divine source of theological knowledge by faith: 'We do not proceed from theological principles to theologized, but we are unshaken in these [principles] of ours, being God-taught (emphasis added) (Palamas 2013, pp. 5, 81).

Thus, while the scientist seeks to discover the composition of sensible things, the causes and effects that trigger or accompany physical phenomena in nature, imposing order on the data collected from the surrounding world, looking for rational, autonomous patterns and explanations, instead, the theologian does not reject the world and the things in it, but receives their meanings through senses purified by sinful lusts, in his mind freed from their passionate understanding. Moreover, all these meanings of things in the world are not 
Comşa Fr. Petre, Munteanu Costea (2020), The apodictic method and the dialogue between theology and science (I), The Journal of Philosophical Economics: Reflections on Economic and Social Issues, XIV (1-2), 136-176

viewed by a theologian in an autonomous way but 'in a close connection with God, through the work of grace that mediates this enlightenment' (Mihalache 2016, p. 246).

We can observe here the deep discontinuity between the two distinct paths of knowledge (which we discussed at the beginning): the scientist is engaged in a knowledge 'on his own', based exclusively on his own cognitive powers, while the theologian's knowledge has the very power infused by God as the source and the driving force. So the knowledge of the latter does not lie in words but in work; it is not based on abstract notions, reasonings and syllogisms, but on life, the reality of man's encounter with God, the reality of a life in Christ of the Church, the experience of ecclesial life.

And this proves to be crucial in terms of the truth that each of the two paths of knowledge shares. Referring particularly to this aspect, St. Gregory Palamas writes:

'He who has gathered his way of thinking from the outside wisdom [by scientific knowledge - our comment], even if he has shared some truth, yet, arguing only by word - which, being word, always fights with another word - he became acquainted with a fragile wisdom, sometimes contradicting himself (...) (emphasis added) (Palamas 2015, pp. 287, 289).

Instead, he who seeks the wisdom of God, that is, "he who seeks and does the will of God' is 'the one whose thoughts his life bears witness to', he is the one who has "his word materialized in deed and his deed speaking on his behalf" that is, he accomplishes 'by himself in a thoughtful way the things put forward and himself being thoroughpaced by them in a mysterious way (...) he also has the approval from the heavenly ones through the coming and secret appearance of the Spirit, and sometimes it reaches, through spiritual prayer, the sight and ascension that are above perfection' (emphasis added) (ibidem).

\section{Hierarchical harmony as a binder of the Orthodox theology-science dialogue}

If what argued in the previous section is correct, it means that one of the defining dimensions of the Orthodox theology-science dialogue is given by the discontinuity relationship, where knowledge acquired through scientific reasoning, is placed in relation to the divinely revealed one. In the following 
Comşa Fr. Petre, Munteanu Costea (2020), The apodictic method and the dialogue between theology and science (I), The Journal of Philosophical Economics: Reflections on Economic and Social Issues, XIV (1-2), 136-176

pages we will try to argue that another defining dimension of the dialogue consists in the hierarchical harmony relationship that mediates the meeting between the two, thus transgressing the discontinuity and making the theologyscience dialogue possible and viable.

The 'hierarchy' we refer to here does not however take into account the generally acknowledged meaning of the notion, namely, a system of consecutive subordination of the lower degrees or steps to the higher ones. Etymologically, the 'hierarchy' considered here comes from ieros $=$ saint and arche $=$ principle, i.e., the principle of holiness, therefore hierarchy means in our context the order (settlement) after holiness (cf. Fr.Petre Comșa). St. Dionysius the Areopagite says in this regard that hierarchy is a holy ordinance, and science and work similarly to the divine model are elevated to imitation of God by the enlightenments given to them by God, in its measure (cf. Fr.Petre Comșa).

Starting from these, we could say that the hierarchical relationship through which Orthodox theology encounters science derives, on the one hand, from the fact that the revealed truth is divine, while the scientific truth is from God, so that the dialogue that can take place between knowledge by means of religious faith and knowledge through scientific reason means that the latter, through its openness to humble thought, should be enveloped in an edifying and enlightening manner by the former.

The hierarchical relationship, on the other hand, also relates to a different cognitive gain brought by the two ways of knowledge. St. Basil the Great considers in this regard that, if there is any kinship between these two kinds of teachings, their knowledge can be useful, and if there is no kinship, it is important to know the difference between them, putting them face to face; and this is not a trivial matter, to find out which is better (St. Basil the Great 1986, p. 568). And the same Saint also shows: 'But some people despised the teaching given by the divine words and dealt with geometry ... or astrology. Many were concerned with poetry, rhetoric and the discovery of sophistry. Therefore, because many have neglected the knowledge of God, in their zeal after acquiring this knowledge, growing old in the search for vain teachings, it is necessary to know the teaching (given by the divine words - our comment), to choose the useful teaching and avoid the vain and harmful one' (emphasis added) (St. Basil the Great 1986, pp. 473-4). And St. Gregory Palamas, pointing out that one's 
Comşa Fr. Petre, Munteanu Costea (2020), The apodictic method and the dialogue between theology and science (I), The Journal of Philosophical Economics: Reflections on Economic and Social Issues, XIV (1-2), 136-176

preoccupation with science in his youth is good, because it exercises his mind to become more penetrating in discerning things, however, points out: '... but to remain attached to them all the time is bad ... Of course, I would not stop those who want to deal with the sciences, that is, those who have not chosen their monastic life. But I do not advise anyone to permanently attach to them. But I urge them not to expect anything specific about God from those sciences' (Stăniloae 1993, p. 27).

Which does not mean, however, that scientific knowledge is relentlessly bad: on the one hand, it is a good thing to engage with sciences, which exercises the sharpness of the soul-eye, but on the other hand, it is bad to adhere to them until old age. It would be good if, after having exercised it in moderation, man shifted his will to the best and most enduring spiritual preoccupations, much reward being brought to him by the contempt of the discursive sciences (Palamas 2015, p. 53). And, in conjunction with the teachings of the Holy Fathers, the great Romanian theologian Dumitru Stăniloae states that in the presence of the grace of the Holy Spirit, scientific knowledge can also be of some use (Stăniloae 1993, p. 32) as this type of knowledge, through its results, can clarify further the things said in the Holy Scripture, that is, in the revealed truths: scientific knowledge can contribute to the clarification of the Scripture but only if we have the only key to Scripture, the grace of the Holy Spirit (Stăniloae 1993, p. 27).

It means that, although the approach to theological knowledge is in no way related to any method used by the sciences, and mystical knowledge is opposed to rational or dialectical knowledge, and theology is revealed to be something other than any other science (Mihalache 2016, pp. 302, 246-247), still, the dialogue can bind when scientific knowledge also has as a starting point 'the power set in motion by the the Holy Spirit' (Palamas 2015).

And, in our opinion, this is exactly what lies behind the notion of the hierarchyin-harmony relationship between theological and scientific knowledge (to which we referred a little earlier in our paper). The same wonderful Saint Gregory Palamas says in this regard: 'Outer educational instruction [scientific knowledge - our comment] can never be made spiritual if it is not combined, in addition to faith, with the love of God - or rather if it is not reborn by the love and grace that comes from it and thus becomes other than the first [in the sense that other than what it was originally, namely scientific knowledge - our comment], that is 
Comşa Fr. Petre, Munteanu Costea (2020), The apodictic method and the dialogue between theology and science (I), The Journal of Philosophical Economics: Reflections on Economic and Social Issues, XIV (1-2), 136-176

a new one (...) as one which is spiritual because it is subject to the wisdom of the Holy Spirit, and knows, and receives, His charisms' (emphasis added) (Palamas 2015, pp. 61, 63). Trying to interpret the words of the Saint Gregory Palamas we will conclude the following:

- The basis of patristic theologizing is the truth coming from the Holy Spirit, His power shared with the Fathers.

- We ascend to the knowledge of God not by the common notions processed autonomously by our intellect, but by the grace of God.

- The starting point in the knowledge of God is the power inspired by the Holy Spirit.

- Scientific knowledge can also be part of this ascent to the truth of Creation only if the scientist engages himself in such a spiritual ascent and opens himself to his own transfiguration under the work of grace of God.

- The work of its own transfiguration of scientific knowledge under the power of grace hypostasizes the reality of the together-working between the patristic teaching and the scientific analysis, testifying in this way to the hierarchical nature of the dialogue between them.

\section{On the apodictic and antinomic issues within the dialogue of the Orthodox theology with science}

But the question arises: does the scientist have a method at his disposal that can guide him in the ascent of this joint work? That is, which can bring together in a viable hierarchical structure (from a gnoseological, hermeneutic and heuristic point of view) the methodology of scientific and theological knowledge. Our view is that this method is not only possible, but it already exists. It does not have to be invented or discovered but only reconstructed as in a puzzle game, from the ideas, analyses, and demonstrations that can be found in the work of some of the theologians, philosophers, and scholars of times closer or farther from us. This method may well be called the apodictic method based on antinomic logic. Therefore, we further intend to follow the path of reconstituting this method in several successive steps by first addressing the problem of truth in theology and science, then that of the antinomic logic, to finally reach the actual configuration of the apodictic method. 
Comşa Fr. Petre, Munteanu Costea (2020), The apodictic method and the dialogue between theology and science (I), The Journal of Philosophical Economics: Reflections on Economic and Social Issues, XIV (1-2), 136-176

\section{On the Divine Truth and human truth}

Saint Seraphim of Sarov teaches us that the purpose of (Christian) life is the acquisition of the Holy Spirit. But through the Holy Spirit, through the Spirit of Truth, the Truth is proclaimed to man. And here, at the moment of the acquisition of the Spirit, at the moment when, by cleansing of burden of sins, 'consciousness rises above the double boundary of space and time and enters into eternity' here, at this moment of annunciation, '... He who announces the Truth and the announced Truth totally coincide. In the manifestation of the Spirit of Truth, that is, in the tabernacle light, the form of Truth and the content of Truth are the same' (Florenski 1999, p. 96). But, perceived and appropriated by man, the knowledge of the Truth descends over time and space, in the temporal dimension which accompanies the variety of persons and in the spatial dimension which accompanies the variety of society (ibidem). Through the descent into time and space, however, the immediate unity of form and content is subjected to a double rupture: the knowledge of the Truth becomes a knowledge about the Truth, on the one hand; and, on the other hand, knowledge about the Truth simply represents a truth.

There is no doubt that along with the Divine Truth there is necessarily the human truth, if along with God, there is also the man, the creature. The existence of truth is only another expression of the very fact of the existence of the creature as such, that is 'of the creature that is found in time through its personal multiplicity and in space through its social multiplicity' (ibidem).

Although given in creature, the truth must be the monogram of the Divinity: 'Being here, it must be as if it were not from here. Through the colours of the contingency, it must outline the Non-Contingent. The indestructible Adamant of the Godhead must always fit in the fragile vessel of human words' (Florenski 1999, p. 97). Man is born and dies and generation after generation succeeds, but the truth must remain, not being subject to corruption and decay. People argue and contradict each other but the truth must be indisputable and above any dispute. People's opinions change from country to country and from year to year, but the truth everywhere and always is one and the same. In short, the truth is something that everyone has believed in everywhere and always, because being universal in reality and in the proper sense of the word, as the very significance 
Comşa Fr. Petre, Munteanu Costea (2020), The apodictic method and the dialogue between theology and science (I), The Journal of Philosophical Economics: Reflections on Economic and Social Issues, XIV (1-2), 136-176

and meaning of the word shows, it is what encompasses everything as much as possible (ibidem).

The problem we face when we share such a vision of the condition of human truth is this: how is the Divine Truth presented to human reason? Or, more rigorously and deeply expressed: how can one construct the unconditional formula of the Divine Truth from the conditioned material of the human mind? This means, in our understanding, that we have a duty to ask ourselves about the properties, structure, and nature of human truth, a truth which, though given by God, is nevertheless given in mankind and to mankind. In other words, the question regarding the formal structure of human truth and its rational organization proves to be legitimate when its content is the Truth itself. And a fact that should not be neglected in the context of the analysis we are undertaking in this paper is that by finding answers to these questions we open the beginning of the path for reconstituting the specific and independent method of interdisciplinary science-theology dialogue.

\section{The Truth that envelops the truth}

Looking for the answer to the question about the logical structure of human truth, we must keep in mind that '... (human) truth is truth relative to the Divine Truth and not to something else, that is, it is in a certain concordance with the Divine Truth. The form of truth is able to maintain its content, the Divine Truth, only when, in some way - even symbolically - has in itself something of the Divine Truth' (emphasis added) (Florenski 1999, idem). In other words, human truth must necessarily be the emblem of a certain fundamental property of Divine Truth. And perhaps the most convenient proof in this regard is the antinomic nature of human truth as an emblem of the antinomic character of the Divine Truth.

\section{Divine Truth as an antinomy}

Let us start from the crucial fact that antinomic thinking is used by Christ the Savior Himself: 'For whosoever will save his life shall lose it: and whosoever will lose his life for my sake shall find it' [Matthew 16, 25]. In fact, His whole teaching is paradoxical, antinomic [1]: if you want to rule, serve; if you want to be exalted, 
Comşa Fr. Petre, Munteanu Costea (2020), The apodictic method and the dialogue between theology and science (I), The Journal of Philosophical Economics: Reflections on Economic and Social Issues, XIV (1-2), 136-176

humble yourself; if you want to regain your innocence, plead guilty; if you give what you do not have, you will gain what you have given to others.

On the other hand, the antinomic character of Divine Truth is a heavily debated and argued subject in Orthodox theology. For example, it is considered that in the case of dogma (the theological term for what we call here the divinely revealed Truth), reason is suspended from its (apparently natural) rights, the logical laws of identity and contradiction losing their authority (Sturzu 2009, p. 282). In the same sense, the Orthodox theologian Paul Evdokimov points out: 'Thus, God is One and Triune at the same time, but $\mathrm{He}<$ is neither a triad nor a monad, as we know them by numbers $>$; the two natures unite in one divine hypostasis of Christ; he is no longer the apostle Paul, but Christ lives in him; from all it is seen that it is not the same or another, but the same and another at once. In this world of pure evidence, the tertium is always datur, but in order to understand it we must go through evangelical metanoia' (Evdokimov 1996, p. 190).

The authentic and full experimenters of faith, the Holy Fathers, have testified over the centuries that the closer we get to God, the clearer the contradictions. The mysteries of faith, far from being secrets that we must not divulge, are inexpressible, unspoken, and indescribable experiences of the Divine Truth ('Jesus saith unto him, I am the way, the truth, and the life' - John 14, 6), which cannot be otherwise hypostasized in words than in the form of antinomy, which is both 'yes' and 'no'. In fact, the Holy Book is full of antinomies. It antinomically intersects not only the judgments of different biblical authors (for example, with the Apostle Paul, the atonement is made by faith, while in the Apostle James by deeds, etc.) but also the judgements of one author; and not only in his various writings but also in one writing; and not only in different passages but also in one passage. The antinomies stand together, often in the same verse, even in the strongest moments, which, like a strong gust of wind, shake the soul of the believer.

For example, the Apostle Paul. His brilliant religious dialectic consists of a series of ruptures: he jumps from one antinomic statement to another. Sometimes the antinomy is contained even in the stylistic rupture of the continuity of the story, in a formal asyndeton [2]: contradictory and mutually exclusive rational judgments are pointed at each other. Therefore, antinomies are constitutive elements of religion (if we think about it rationally): thesis and antithesis, like 
Comşa Fr. Petre, Munteanu Costea (2020), The apodictic method and the dialogue between theology and science (I), The Journal of Philosophical Economics: Reflections on Economic and Social Issues, XIV (1-2), 136-176

warp and weft, weaving the very fabric of religious experience. Where there is no antinomy, there is no faith (Florenski 1999, p. 108).

\section{Human truth as an antinomy}

If, as we have already argued, human truth must necessarily be the emblem of a specific fundamental property of the Divine Truth, and if such a property of the latter is its antinomic character, then we understand that human truth must also be an antinomy. This is what we will be analyzing next, following the historical 'destiny' of the antinomy in logical thinking, mainly through the tension that has manifested over time between the aspiration for the omnipotence of logical formalism and the main forces that opposed such an aspiration (i.e., paradox/antinomies).

\section{The evolution of logical formalism over time}

Following the ideas of the reputed Romanian logician Petre Botezatu, we would say that modern logic bears the stamp of its origin: it was created by mathematicians and for mathematicians (Botezatu 1983, p. 7). Thus, mathematical logic (as it is generally called the modern logic) was constituted and perpetuated primarily as a logic of mathematics. The ideal pursued has been and still is to offer mathematics, which is a discipline of accuracy and rigor, even these qualities being maximized. This way, mathematicians aspired to master the operations of logical thinking as they mastered the amount of mathematical data, and to become aware of the mechanisms of demonstrations as they were aware of the findings of mathematical information (ibidem).

Aristotle took the first significant steps on this path, and from his approach which was passed on by many generations of devoted disciples - developed what is now called classical logic (where 'classical' is opposed to 'modern'), or even better named, the traditional logic. Aristotelian syllogistics, although it represented the first form known to us of an axiomatic system, failed however to generally enjoy the acceptance within the world of mathematicians. Firstly, due to the fact that mathematicians as a rule do not operate in their demonstrations this model although it plays an important role in conversational language and in other areas of knowledge. Secondly, although Aristotle had advanced towards symbolizing the logical language (by introducing logical variables), his 
Comşa Fr. Petre, Munteanu Costea (2020), The apodictic method and the dialogue between theology and science (I), The Journal of Philosophical Economics: Reflections on Economic and Social Issues, XIV (1-2), 136-176

achievements did not prove to be to the liking of mathematicians, not being formalized enough to constitute a calculation. Under these circumstances, mathematicians 'felt compelled' to construct a logic of their own, a mathematical (or symbolic, modern) logic (Botezatu 1983). The success should not be neglected although it had been gained over time and with remarkable efforts, having to overcome enough resistance.

As to the success to which we have referred, it must be shown that, disregarding the indisputable gains which reverted to the mathematical sciences - now in a superior form of construction and exposition - logic itself has been thus driven into a far-reaching scientific revolution: many hitherto unknown logical laws were discovered (able to master situations of great complexity), logical structures of appreciable power were set up (able to organize at the highest level the most different sectors of scientific knowledge), difficult problems have arisen and have been solved that modern science has brought to light.

In fact, it appears that modern logic is indeed the logic of modern science. It is the background on which the researches of mathematical (symbolic) logic have advanced substantially and diversified a lot so that today there are several variants of scientific language able to formalize mathematical and logical theories and even theories of natural and social sciences. Of course, formal languages are not perfect and do not aim to solve all the problems of scientific knowledge, but the fact is that they are available to us (Botezatu 1983, p. 11).

Moreover, modern logic justifies its value not only by the scientific applications it generates but also by its significance as a theory of logical thinking and logical language. In this sense, the new logic has enriched the traditional logic with an impressive repertoire of logical laws, deductive procedures, ways of constructing scientific theories and, at the same time, with determining the effective power and limitations of these processes. So, we do not think it is an exaggeration to say that modern logic today is an impressive body of concepts and theories that are imposed with the authority of formal rigor.

On the other hand, as it was said before, these remarkable developments appeared over time and with serious efforts, having to face many obstacles, some of them not yet being overcome [3]. Probably one of the major obstacles that had to be overcome in this regard was the historical controversy over the nature of 
Comşa Fr. Petre, Munteanu Costea (2020), The apodictic method and the dialogue between theology and science (I), The Journal of Philosophical Economics: Reflections on Economic and Social Issues, XIV (1-2), 136-176

mathematical judgments. The starting point of the controversy was Kant's conception of the division of judgments into synthetic and analytical, the former being defined as extensive (the predicate adds a new note to the subject), and the latter as intensive, explanatory (adds nothing to the subject). Kant also distinguishes between a priori judgments (which are grounded in pure thinking) and a posteriori judgments (which come from experience). For Kant, mathematical judgments are all synthetic (thus increasing knowledge) and a priori (necessary and universal). He argues that it is impossible to have a sensitive intuition (sensitivity being one of the two faculties of knowledge, along with the intellect) without the 'forms' of space and time. The representation of these forms is prior to sensations so they are a priori forms. As intuition makes synthesis possible and mathematical judgments are closely related to space and time, these judgments are synthetic a priori (Kant 1994, p. 45). As a conclusion, '... for him, pure mathematics is not analytical; it is synthetic a priori because it refers to (describes) space and time' (Korner 1965, p. 45).

Decades later, representatives of logical empiricism will reject Kant's view on mathematical judgments. For empiricists, there could be accepted only statements that can be deduced in a purely logical way, analytically, or that are confirmed by experience, synthetically a posteriori. Consequently, starting with the middle of the 19th century, logic and mathematics became closer. Towards the end of the 19th century, Frege [4], starting from the idea that mathematical statements are a priori analytical [5], tries to prove that mathematics is a branch of logic (so mathematics is covered by logic). It should be noted here that by saying that the asserted sentences of arithmetic have an analytical character, Frege considers the fact that they are 'logical truths', conferring to the word 'analytical' its own meaning (Frege 1977, p. 46).

Frege aims to construct a very precise symbolic language that he calls the 'formal language of pure thought.' The new language, 'totally constructed of signs, from which any ambiguity can be eliminated', is like a microscope compared to the human eye (represented by the spoken language) (Dumitriu 1969). Replacing the notions of 'subject' and 'predicate' with those of 'argument' and 'function', the mentioned author lays the foundations of the propositional calculation [6], completely axiomatized. Frege observes that numerical data, referring to 
Comşa Fr. Petre, Munteanu Costea (2020), The apodictic method and the dialogue between theology and science (I), The Journal of Philosophical Economics: Reflections on Economic and Social Issues, XIV (1-2), 136-176

characteristics and not to signals, are related to the notion [7], and not to the object. [8]

\section{The first fissures in the formal logical system}

With Frege's contributions, the process of formalizing mathematics by exploring its logical foundations did not seem to encounter any obstacles of a theoretical nature. Suddenly, however, in 1902, Bertrand Russell told Frege that he had discovered a contradiction at the base of his system: the multitude of multitudes that do not include themselves, encompasses itself when it does not encompass, and vice versa (Botezatu 1973, p. 47). This contradiction remained in the history of logic as the 'Russell's paradox', or 'class paradox'. With this paradox, we enter a new period of prolonged crisis of science foundation that had been considered, until then, of an indisputable clarity: mathematics and logic. Thus, 'instead of bringing a new certainty, the new logic will establish the permanence of the provisional' (Frege 1977, p. 46). Frege himself would give up the development of his formalism, viewing it as a hopeless situation, the logical program being taken over by Russell and Whitehead.

In any case, the situation was not unprecedented as the paradoxes had been known since the times of ancient Greeks, in that they violated two principles of the Aristotelian logic: the principle of non-contradiction (both a statement and the negation cannot be true simultaneously) [9] and the principle of the excluded third party (within a logical system, a sentence can be true or false; there is no third possibility) (Aristotle 1961). In this respect, the best known is the paradox of the liar [10]. The problem that arises here (in all versions) is that of selfreference: the statement refers to itself. It is a problem that we will return to a little later as it is extremely important in Russell's type theory and language level theory introduced by Tarski.

Next, we will deal with Russell's paradox and its consequences that led to the emergence of type theory. Russell divides classes (or sets) into two: classes that are contained in themselves as an element (e.g., the class of all abstract notions is an abstract notion, so it contains itself) and classes that are not contained as an element (such as the class of all mammals, which, not being a mammal, does not contain itself) (Dumitriu 1969). 
Comşa Fr. Petre, Munteanu Costea (2020), The apodictic method and the dialogue between theology and science (I), The Journal of Philosophical Economics: Reflections on Economic and Social Issues, XIV (1-2), 136-176

Denote by $\Gamma$ the class of all classes not contained as an element:

$$
\Gamma=\{\mathrm{K} \mid \mathrm{K} \notin \mathrm{K}\}
$$

Since each class contains or does not contain itself, a third situation being excluded, there are only two possibilities: either $\Gamma$ is self-contained or not. If $\Gamma$ is contained in itself, taking into account the fact that it contains only the classes that are not contained in themselves, it means that it is not contained. Conversely, if $\Gamma$ is not contained, as it contains all classes that are not contained, it must be contained. In conclusion, a contradiction is reached: the class $\Gamma$, of all classes that are not contained as an element, is contained in itself only when it is not contained in itself [11].

Such paradoxes 'constitute one of the greatest obstacles in the establishment of logic as a mathematical science and in the logical substantiation of mathematics' (Dumitriu 1969). The illusion of clear and distinct ideas seems largely compromised, and this occurs in the realm of the sciences that seemed least prone to such a crisis: logic and mathematics. 'One by one, the paradoxes of Burali-Forti, Cantor, Russell, Richard and others, shattered the idea of the "ideal" character of mathematical constructions, imposing here, as everywhere, the principle of the relativity of knowledge (emphasis added) (Enescu 2003). In any case, it is obvious that things could not be left in such a state, so several solutions to Russell's paradox have been proposed (Enescu 1967). Interestingly, the most important and widely accepted to date was proposed by Russell himself (Dumitriu 1969), a solution that he called type theory. [12]

Trying to overcome some of the difficulties of type theory, Russell later developed a branched theory of types. However, the system became cumbersome so the first attempts to simplify it appeared in the third decade of the twentieth century. An important contribution in this regard was made by Frank P. Ramsey who divided the paradoxes into two different groups that would later be called logical paradoxes (Group A) and semantic paradoxes (Group B). Group A includes, among others, Russell's paradox, and Group B, among others, the paradox of the liar.

Semantic paradoxes are not therefore part of the category to which the classical theory of types can be applied, while logical paradoxes can be solved, as we have seen, with the help of simple type theory. Consequently, we can infer that 
Comşa Fr. Petre, Munteanu Costea (2020), The apodictic method and the dialogue between theology and science (I), The Journal of Philosophical Economics: Reflections on Economic and Social Issues, XIV (1-2), 136-176

Russel's branched theory of types can be abandoned as Ramsey did. So, a solution remained to be found for solving the semantic paradoxes.

Starting from Russell's own suggestion to rank the notions of 'true' and 'false' by type, the solution was found due to the contribution of Rudolf Carnap and, especially, of Alfred Tarski. The latter distinguishes between the sentence as such and its name. For example, 'the horse has four legs' is the name of the sentence the horse has four legs. Semantic paradoxes appear, says Tarski, because no distinction is made between the situation in which an expression is used to speak of an object independent of it and the situation in which the expression itself is the object of the formulation. For example, if it is stated 'the horse is an animal', the horse is designated as an object, while in the sentence 'the word <horse $>$ has five letters', the object is the expression itself. In the first case, the expression is taken in suppositione formali (in formal suppositions), and in the second, in suppositione materiali (in material suppositions) (Enescu 1967). Returning now to the original example, the statement 'the horse has four legs to walk with', the underlined sentence appears in suppositione formali, while the statement 'the sentence $<$ the horse has four legs $>$ contains four words', it is in suppositione materiali.

So, it can be said that the closed nature of the language creates confusion. To 'open' it, Tarski introduces the language levels. Thus, he identifies the objectlanguage, the meta-language (the language in which we talk about objectlanguage), the meta-meta-language (the language in which we talk about metalanguage). If we consider a logical system $\mathrm{S}$, which operates with the notions of 'true' and 'false', they cannot be rigorously defined within the same language $\mathrm{S}$, but only in a meta-language, $\mathrm{S}_{1}$, since the concepts of 'true' and 'false' belong to the meta-logical system $\mathrm{S}_{1}$ that speaks of the language of the system $\mathrm{S}$. Likewise, there will be a meta-meta-logical system, $\mathrm{S}_{2}$, in which we speak of $\mathrm{S}_{1}$ etc. The number of systems is practically unlimited. Obviously, 'the meta-language has a higher order than the language under investigation' (Tarski 1956, p. 52). Although Tarski initially (1932) considered it impossible to construct a metalanguage for a formalized language of infinite order, he would later (1956) avoid making an explicit statement in this regard. Using the described model, the contradiction in the paradox of the liar is avoided, as the liar cannot say anything 
Comşa Fr. Petre, Munteanu Costea (2020), The apodictic method and the dialogue between theology and science (I), The Journal of Philosophical Economics: Reflections on Economic and Social Issues, XIV (1-2), 136-176

about the truth value of the 'I lie' sentence in the same system in which this sentence was constructed.

In conclusion, just as the confusion of types in Russell's theory produces logical paradoxes, the confusion of language levels in Tarski's model leads to semantic paradoxes. There is a common idea of the two systems: a contradiction that cannot be resolved at one level, can be resolved at a higher level.

\section{Recovering the creative potential of the paradox}

Anton Dumitriu claims that by separating the system from the meta-system, the meta-theory (the $\mathrm{S}_{\mathrm{n}}$ system in Tarski's level model) has a particular, determined object, namely the formal system $\mathrm{S}_{\mathrm{n}-1}$. For this reason, meta-theories lose their purely formal character. Formal logic should however be independent of the content to which it applies. So, Anton Dumitriu's conclusion is that the emergence of meta-theories is a failure of formalism from a logical point of view (Dumitriu 1969).

In fact, the limitations of formalization of a logical-mathematical system were highlighted as clearly as possible by Kurt Gödel, who started from the question of whether we could not stop at a certain level, one of the languages managing to be their own meta-language. As it does not matter what symbols are used to encode a logical-formal system, Gödel associates natural numbers with the classical notions of logic. Thus, a formula can be represented as a finite series of natural numbers. The series is assigned, according to a specific algorithm, a number called 'the Gödel number' of the formula. A series of formulas receives a 'Gödel number' using the same procedure. Being a string of formulas, the demonstration will have an associated 'Gödel number'. Thus, the statements regarding the formalization of mathematics (which are part of metamathematics) become statements about natural numbers so they also belong to mathematics. Through this ingenious procedure, meta-mathematics overlaps with mathematics. Mathematics thus becomes its own language.

Starting from this premise, Gödel demonstrates that one of his undecidable sentences, that is, which cannot be said to be true or false, is precisely the one that states that the system is non-contradictory. Gödel thus proved the incompleteness of any formal logical system by stating the famous theorem that 
Comşa Fr. Petre, Munteanu Costea (2020), The apodictic method and the dialogue between theology and science (I), The Journal of Philosophical Economics: Reflections on Economic and Social Issues, XIV (1-2), 136-176

bears his name (also known as the 'incompleteness theorem'): 'There are undecidable sentences in any class of non-contradictory systems.' In essence, Gödel's idea can be expressed as follows: 'It cannot be proved whether this statement is true or false.'

Either it is assumed that the above statement is true, or it is false, it reaches a circular, self-referential paradox, such as the one analyzed by Russell. Consequently, a formal non-contradictory system - complex enough for the arithmetic to be formalized in it - is incomplete in the sense that undecidable sentences can be rigorously constructed. The demonstration that such a system is free of contradictions can therefore only be made outside the system. In short, 'the price of the non-contradiction of a system is its incompleteness' (Marcus 1984). Paradoxes have long been perceived as an anomaly, a negative phenomenon which was intended to be eliminated. With the formulation of Gödel's theorem, however, the paradox can no longer be seen as a limitation of thought, but, on the contrary, as a possible opening to the investigation of a new reality as 'the heart of any creative thinking' (Marcus 1984).

Concluding, we could state that as a result of the emergence of paradoxes in mathematics and logic, the abstract (absolutizing) way of appreciating the value of these sciences and, first of all, the illusion of total perfection of mathematics and the absolute character of the laws of formal logic have suffered a severe blow. Such attempts to resolve the paradoxes stimulated however their evolution; with the emergence of paradoxes, we are invited to enter a new world of the Real (Enescu 1973).

Although Russel's type theory is considered the most important solution to logical paradoxes, there are voices that argue that it rather avoids the created vicious circle (Dumitriu 1986), having only an 'ad-hoc remedy' character, failing to establish the 'cause of the disease', and it was simply hoped that this way contradictions would be avoided (Korner 1965, cf. Berian 2010, p.54). This weakness of his theory was also acknowledged by Russell himself: 'Type theory does not belong at all to a finite part of our system. The need for a doctrine of types is unquestionable but this doctrine still needs a precise form' (Dumitriu 1969). 
Comşa Fr. Petre, Munteanu Costea (2020), The apodictic method and the dialogue between theology and science (I), The Journal of Philosophical Economics: Reflections on Economic and Social Issues, XIV (1-2), 136-176

We now allow ourselves a remark regarding our preoccupation by highlighting the inherent limitations of formalization: Russell's logical-mathematical system is the first complete and explicitly axiomatized logical system, as well as the first completely formalized logical system (operating only with signs and rules). However, out of a desire to eliminate the lack of rigor, Russell tried unsuccessfully to remove completely the intuition from his system, a failure which Russell saw as 'a certain failure of formalism in generally, in the symbol itself always remaining some residue of intuition' (Dumitriu 1969).

For Carnap and Tarski, as for Russell as well, the ontological dimension of logic is neglected in favour of abstract formalism. Hence Carnap's disregard for traditional logic (rooted in the Aristotelian system), calling it 'anemic.' Russell, in his turn, calls the syllogism a 'solemn charlatanry'. In this context, we believe that it is worth mentioning the valuable idea expressed by Anton Dumitriu in his relatively older work, where he expresses his conviction that this misunderstanding shown by the logicians cited above regarding the Aristotelian logic 'has its origins in the loss of the contact of logic with reality and therefore with ontology' (emphasis added) (Dumitriu 1941).

It is interesting to observe that it was precisely intuition, which Russell thought should be removed from a formal system, that constituted for L.E.J. Brower [13], in the first decade of the last century, the starting point for the solution he put forward to the problem of paradoxes. Brower argues that mathematics is independent of logic and language, having intuition as its only source, but the language in which mathematical construction is expressed is sometimes contradictory. Mathematics should not be confused with mathematical language: 'the experience of mathematical intuitions and constructions should not be confused with its linguistic description and communication' (Korner 1965, p. 55).

Starting from the principle that 'any sentence that has a content must indicate one or more states of things, well-determined and accessible to our experiences' (Dumitriu 1941), Brower underlines that, in the field of infinite multitudes, it is meaningless to say that an element belongs or not to such a multitude due to the fact that we cannot indicate this. One can speak of the content of a sentence only when it can be intuitively linked to a state of affairs, or to the corresponding construction (Dumitriu 1968), so Brower restricts the validity of the principle of the excluded third party [14] only to the area of finite multitudes (as is the case 
Comşa Fr. Petre, Munteanu Costea (2020), The apodictic method and the dialogue between theology and science (I), The Journal of Philosophical Economics: Reflections on Economic and Social Issues, XIV (1-2), 136-176

with the natural sciences, by the way). For example, if we consider the sentence ' $x$ has the property $y$ ', stating that it is absurd and false, it does not mean that it can be deduced from this that the sentence is necessarily true [15]. Brower believes that by doing so, he manages to eliminate the paradoxes related to infinite multitudes [16].

It is remarkable that intuitionism arose from the desire to bring logic closer to the ontological or, in other words, pure thinking of immediate reality. By contrast, all the more relevant in this respect are now the words of Russell, who stated, referring to the nature of modern logic: 'It is thus evident that the knowledge of logical forms and the knowledge of real things are something totally different' (Dumitriu 1968). In conclusion, it is evident that intuitionism has brought logic closer to reality by restricting the validity of the principle of the excluded third-party.

\section{Multipurpose logics and the included third-party principle}

As noted earlier, there were paradoxes in the fourth decade of the last century, both in logic and in mathematics: sentences that could not be declared true or false because as a contradiction was reached in any of these situations. Moreover, the contradiction seemed impossible to be avoided in quantum mechanics as well; wave-corpuscle dualism, Heisenberg's principle, the probabilistic fundamental character of quantum mechanics was paradoxical from the perspective of classical physics. In this context, the idea began to gain ground that a sentence could have a value of truth other than 'true' or 'false', an idea that led to the reconstruction of the logical conception of the structure in the theory of physics [17].

The first one to develop a consistent non-contradictory polyvalent logical system was the Polish logician J. Lukasiewicz, starting from the idea that, just as challenging Euclid's postulate favoured the emergence of non-Euclidean geometries, polyvalent logics could be constructed if we abolished the general accepted validity [18] of the excluded third-party principle [19].

Lukasiewicz's logic is trivalent (see Dumitriu 1969), admitting three values for sentences: true (marked with ' 1 '), false (marked with ' 0 ') and possible (marked with ' $1 / 2$ '). In this system, the negation (marked with ' $N$ ' by Lukasiewicz) of the 
Comşa Fr. Petre, Munteanu Costea (2020), The apodictic method and the dialogue between theology and science (I), The Journal of Philosophical Economics: Reflections on Economic and Social Issues, XIV (1-2), 136-176

'false' is 'truth', the negation of 'possible' is 'all possible' and the negation of 'truth' is 'false':

$\begin{array}{llll}\mathrm{p} & 0 & 1 / 2 & 1 \\ -\mathrm{p} & 1 & 1 / 2 & 0\end{array}$

In this context, we can say that current physics cannot be interpreted in the light of bivalent logic since the quantum particle should have and, at the same time, not have a corpuscular (or undulating) nature. In trivalent logic, however, this constraint is not valid, so the two natures of the micro-particle can exist simultaneously, without leading to a paradox. Moreover, admitting the 'possible' as the value of 'truth', polyvalent logic agrees with the probabilistic nature of the laws of quantum mechanics. After attempts to substantiate a logic adapted to the new quantum theories developed in 1936 by Birkhoff and von Neumann, the following year Paulette Février proposed some trivalent logical schemes aimed to eliminate the contradiction contained in Heisenberg's principle. [20]

\section{The epistemology and logic of Stephane Lupasco}

Seeking to articulate a non-Cartesian epistemology, Stephane Lupasco noticed the immense creative potential of the paradox. The first postulate of his epistemology may surprise someone in terms of formal logic, a logic in which $\mathrm{p}$ and non-p annihilate each other, and for which, contradiction is a threat: "The principle of contradictory complementarity must replace the principle of noncontradiction as a logical foundation' (Lupasco 1940). From Lupasco's perspective, 'behind a specific phenomenon, there will no longer be a question of seeking, as a logical condition of its possibility of existence, that nothing contradicts it, but exactly what contradicts it, which is its complementary contradictory face; the logical condition of its existence is its contradiction' (Lupasco 1940).

Related to Lupasco's approach, it should be noted that Romanian philosopher Constantin Noica also emphasizes the fact that a formal logical system that leads to the marginalization of contradiction 'has no sense of thought or reality, but appears as aberrant if it is passed on to contradictory situations in reality' (Lupasco 1982). The main consequence of the approach proposed by Lupasco is that logic regains its ontological dimension, precisely through the fact that the 
Comşa Fr. Petre, Munteanu Costea (2020), The apodictic method and the dialogue between theology and science (I), The Journal of Philosophical Economics: Reflections on Economic and Social Issues, XIV (1-2), 136-176

paradox is the sign of existence: "Thinking follows directly the being; it must capture the becoming everywhere. Thought seeks the law as peace, even one of contradictions' (Lupasco 1982). [21]

It can therefore be concluded that the Lupascian principle of antagonism introduces contradiction into the functional structure of logic. In the vision of our author, matter is organized as an energetic systematization of events, each energy system obeying the principle of antagonism: 'energy cannot be possible or, at least, perceptible to us outside its inherent antagonism' (Lupasco 1982). Any energy system is subject to antagonistic dynamics in such a way that actualization of one implies the potentialization of the other; the two dynamisms must, during the transition from actualization to potentialization or vice versa, tend towards a state of equal potentialization and mutual actualization. Through the actualization-potentialization alternation, a perpetual antagonism is maintained, which leads to a dynamic balance of the systems; stability and the resistance of a system are all the greater, the more difficult it is for the antagonistic forces to escape from this equilibrium which determines their equal intensity. In the atomic nucleus, the antagonism is stronger than in the atom, so the nucleus is stronger than the atom. Such a reasoning can be applied similarly to larger and larger systems; thus 'starting from the atomic nucleus, on the one hand, the energy systems grow while it shows, on the other hand, a decreasing resistance to disintegration and transformation' (Lupasco 1970). It is interesting to note that the actualization of an event by potentializing (virtualizing) the antagonistic event acts as an effective cause, while the potentialization of an event, becoming 'a possible one that involves dynamism' is the final cause (has a teleological determination).

In Lupasco's system of thinking, any system is a system of systems, in the sense that there is no system that can be considered simple, i.e., made up of a last, unique pair of antagonistic forces. Any object consists of molecules, formed by atoms which, in turn, have constituents; there is no elementary particle without structure. At the level of great infinity, everything happens similarly to the level of the small infinity, any system being, in its turn, part of another antagonistic system. As Lupasco states, "what determines the formation and becoming of systems of systems is always represented by the antagonistic relations of some 
Comşa Fr. Petre, Munteanu Costea (2020), The apodictic method and the dialogue between theology and science (I), The Journal of Philosophical Economics: Reflections on Economic and Social Issues, XIV (1-2), 136-176

antagonistic relations, whose complexity increases with the complication of the systems' (Lupasco 1982).

Considering the above, it is not difficult to observe the similarities among the Lupasco's epistemology, the principle of bootstrap and systemic thinking. Any quantum event is presented at the same time as a wave and the corpuscle, which refers to the continuous-discontinuous dualism, the notion of 'corpuscle' being associated with the discontinuity, and that of 'wave' with continuity [22]. There will always be continuous energies of homogenization represented by photonic particles that do not respect the principle of exclusion of Pauli [23], and the antagonistic discontinuous energies of heterogenization found in electronic particles that are subject to this principle.

Lupasco notices that the tendency of heterogenization and diversification established through Pauli's principle acts against the homogenizing tendency of energy deriving from the existence of the second principle of thermodynamics [24]. Starting therefore from the laws of physics, Lupasco discovers another antagonistic dualism: homogenization-heterogenization; the arrangement of the parts of a system, its structure is the effect of antagonistic microenergy (attraction-repulsion, association-dissociation, bond-rupture) and of the energetic properties that tend in an antagonistic way towards either homogenization or heterogenization' (Dumitriu 1969). Life exists only as a result of this contradictory permanent dualism of homogenization-heterogenization; both extreme differentiation and the attainment of absolute uniformity would lead to eternal stillness, to cosmic death (Nicolescu 2002). The dynamic homogenization-heterogenization dualism has the identity-diversity dualism as a logical correspondent. Lupasco replaces e by i, designating identity and ē by d, meaning non-identity, diversity. Each identity is associated with a contradictory diversity, the actualizing of one generating the potentializing (virtualizing) of the other. If we consider identity and non-identity (diversity) as two truths, one affirmative and the other negative, the two truths generate a relative noncontradiction as one actualizes on the other's potentialization:

$$
\mathrm{iA} \supset \mathrm{dP}, \mathrm{dA} \supset \mathrm{iP}
$$


Comşa Fr. Petre, Munteanu Costea (2020), The apodictic method and the dialogue between theology and science (I), The Journal of Philosophical Economics: Reflections on Economic and Social Issues, XIV (1-2), 136-176

The same two truths generate a relative contradiction when they inhibit each other, preventing the actualization of one on the other's potentialization, a situation corresponding to the T state:

$$
\mathrm{iT} \supset \mathrm{dT}
$$

Thus, one cannot speak of an absolute truth or an absolute falsehood, none of which can be rigorously, perfectly actualized: that is, either the identity is actualized (which implies the potentialization of diversity), or the identity is potentialized (which implies the actualization of diversity), or the two reject each other with equal tension (i.e., the $\mathrm{T}$ state is achieved). We can now conclude that the state $\mathrm{T}$ is the included third party, the third value of the Lupascian trivalent logic, the value of neither true, nor false: 'the same degree of actualization and potentialization of the two contradictory events that reject each other with the same tension and thus prohibit being actual or potential from one another, [...] allow, generate, and explain this $\mathrm{T}$ state or the third possible state' (emphasis added) (Lupasco 1982).

Let us also show in context that Lupasco's logic agrees also with the fact that the knowing subject cannot be separated from the observed object. The actualization of a logical phenomenon e gives it the role of an active agent, being considered in this case a subject; while the potentialization of a logical phenomenon $\overline{\mathrm{e}}$ attributes to the phenomenon a passive character, the character of an object. Therefore, the logical subject and the logical object are always in a relationship of antagonism; as the subject represents the actualization of a certain dynamism and the object represents the potentialization of the antagonistic dynamism, the subject and the object cannot be clearly separated, the subject altering the object and vice versa. As neither actualization, nor potentialization can be absolute, there is no absolute subject or absolute object. This subject-object inseparability was not present in classical physics, precisely because it was started on the premise of an absolute, rigorous actualization.

Finally, Lupascian logic leads to the conclusion that the probabilistic, statistical character of the laws of quantum mechanics is a natural consequence of the relative, incomplete actualization of e accompanied by the relative, incomplete potentiation of è. A law could be non-statistical only if it allowed the absolute 
Comşa Fr. Petre, Munteanu Costea (2020), The apodictic method and the dialogue between theology and science (I), The Journal of Philosophical Economics: Reflections on Economic and Social Issues, XIV (1-2), 136-176

perfect total actualization of e or $\overline{\mathrm{e}}$, which, as it turned out, is an impossibility in the Lupascian system.

As a final remark, Stephane Lupasco's logic starts from reality and returns to it. Noticing that the deepest logic is based on the contradiction springing from the energetic dynamism specific to the antagonistic dualism that manifests itself at macro-physical, biological, and especially quantum (or psychic) level, Lupasco constructs a trivalent logical system based on the so-called included third party principle which allows the conciliation of opposites due to existence of the T state. The new epistemological approach starts from searching the presence of a specific phenomenon, which is the antagonistic phenomenon, and identifying to what extent it is potentialized by the first or potentializes it. During this process, the antagonistic dualism of homogenization (identity) - heterogenization (nonidentity, diversity) plays an essential role. Through this constitutive report of the contradictory complementarity 'we must link the rational and the irrational, the identity and the non-identity, the invariant, and the variant ..., establishing a synergistic relationship between the opposites that until recently have been considered contradictory, their co-existence being inconceivable.

\section{The transdisciplinary vision of Basarab Nicolescu}

In our opinion, the relatively recent research in the field of transdisciplinarity, in particular that of Basarab Nicolescus has been on the same line of legitimizing the logic based on the application of the included third-party principle. The transdisciplinary methodology was built starting from the three postulates rooted in the discoveries of modern science.

(i) The first postulate (of an ontological nature) states that there are different levels of reality and perception in nature and in our knowledge of nature (Nicolescu, Stavinschi 2006).

(ii) According to the second postulate (of a logical nature), the transition from one level of reality to another is made with the help of the logic of the included third party (Nicolescu 2002). In his analyses, Basarab Nicolescu distinguishes between the Real and Reality: 'Real' is what it is, being hidden from us forever, while we can access 'Reality' through knowledge, being 'what resists experiences, representations, descriptions, our mathematical images or formalizations' 
Comşa Fr. Petre, Munteanu Costea (2020), The apodictic method and the dialogue between theology and science (I), The Journal of Philosophical Economics: Reflections on Economic and Social Issues, XIV (1-2), 136-176

(Nicolescu 2002). Along with the pragmatic dimension introduced by the previous definition, 'Reality' also has an ontological dimension: it is not only the product of a construction made by intersubjective agreement but also has a trans-subjective character by the fact that it depends on experimental results. By level of Reality Nicolescu refers to 'a set of systems invariant to the action of a number of general laws', such as, for example, quantum entities, which are subject to laws radically different from those of the macrophysical world (Nicolescu 1999).

According to Basarab Nicolescu, within natural systems there are at least three levels of 'Reality': the macrophysical level, the microphysical level, and the cyberspace-time. To these can be added a fourth level (so far purely theoretical) of supercords. Moving from one level of Reality to another, the laws and concepts change, therefore there is a radical 'rupture', a discontinuity between the two proximal levels, an essential term in quantum mechanics. The way in which the included third-party principle allows the transition from one level of 'Reality' to another is explained by the fact that the unification of the contradictions $\mathrm{A}$ and non-A, located at the same level of 'Reality', can be achieved only at the proximal higher level of 'Reality' through the state $\mathrm{T}$ of the included third party. In the quantum world, representing a different level of 'Reality' than the macrophysical world, the quantum particle will correspond to the state $\mathrm{T}$, which operates the unification of the contradictory entities: wave (A) and the corpuscle (non-A).

Historically, the first two postulates are justified both by quantum mechanics, as stated by Basarab Nicolescu, and, in our opinion, by formal logic, since as logical and semantic paradoxes can be avoided using the theory of Russellian and Tarskian levels; the contradictions of quantum mechanics can be reconciled using a model structured on levels of 'Reality'. It can be easily deducted from the above that a level of 'Reality' is self-destructive if it is completely separate from all other levels of 'Reality' generating antagonistic couples (Nicolescu 1999). In fact, Solomon Marcus emphasizes that 'paradoxes appear as a result of the fact that two distinct levels of knowledge, language, reality, human behavior, etc. are seen as one, overlap, or simply get confused.' For Basarab Nicolescu, 'the logic of the included third party is one of complexity' that does not diminish but only restricts the logic of the excluded third party (which remains applicable in simpler situations). 
Comşa Fr. Petre, Munteanu Costea (2020), The apodictic method and the dialogue between theology and science (I), The Journal of Philosophical Economics: Reflections on Economic and Social Issues, XIV (1-2), 136-176

(iii) We can now state the third postulate - the epistemological one - that of the transdisciplinary methodology advanced by Nicolescu: each level of 'Reality' is what it is because all the other levels of 'Reality' exist simultaneously; the structure of the ensembles of the levels of 'Reality' is therefore a complex one. No level of 'Reality' is privileged.

We believe that it is not difficult to notice the parallel between this postulate and the bootstrap principle. There are degrees of complexity, the complexity of a level of 'Reality' can be perceived as simplicity in relation to another level, which can be complex in relation to its own laws. In the transdisciplinary approach, it is considered that there can be $\mathrm{n}$ such levels ( $\mathrm{n}$ can be finite or infinite), an ensemble that extends with an area of non-resistance to our mathematical experiences, descriptions, representations, images or formalizations, an area in which there is no level of 'Reality' (Nicolescu 1999). It is interesting to note that, in Basarab Nicolescu's understanding, this area corresponds to the sacred, which translates into 'religious feeling', the one that connects people and things, 'a space of peace' beyond words (Nicolescu, Stavinschi 2003). Thus, for our author, the sacred regains its proper place in the process of knowledge: "we are always obliged to refer to the sacred in order to create a coherent discourse on Reality' (Nicolescu 2002). The structure of the levels of 'Reality', in which the logic of the included third-party acts, has opened the impossibility of constructing a complete theory that would describe all these levels as obvious. According to Basarab Nicolescu, this fact agrees with Gödel's incompleteness theorem (whose implications have been previously discussed in our paper).

\section{On the antinomic dimension of truth}

We have previously seen in our paper that classical epistemological models, springing from the illusion of a knowledge in which the subject investigates a reality independent of him, a reality governed by a foreign Laplacean determinism that would constitute the expression of a local causality has proven to be a scientific failure with the advent of quantum mechanics. Positivism, through its disregard for metaphysics, tried to cut the transcendent roots of the human being, which led to a world of 'or-or', the thought being fragmented by a binary logic, in which opposites are excluded; one subject is separated from another, each being separated from nature. To be clear, the ideas had to be 
Comşa Fr. Petre, Munteanu Costea (2020), The apodictic method and the dialogue between theology and science (I), The Journal of Philosophical Economics: Reflections on Economic and Social Issues, XIV (1-2), 136-176

distinct, separated by the scalpel of an indisputable dichotomy. Formal logic was devoid of ontological abstract substratum, separated from reality.

Since the early years of the last century, the efforts of logicians to construct a complete and non-contradictory formalism have been struck by the existence of logical and semantic paradoxes. Attempts to find various solutions to logical and semantic antinomies have led to the emergence of Russell's theory of types (which starts from the idea that logical objects can be ranked by types), by structuring the language on levels, according to Tarski. On the other hand, Gödel's decisive contributions to this issue through his famous theorem that a formal, sufficiently complex, complete and non-contradictory system cannot be constructed - have practically led to the approximation of logic to reality, which occurred, in terms of logic, by intuitively restricting the validity of the excluded third-party principle. With Planck's emphasis on the discontinuous nature of the energy of an atom, the existence of another level of physical reality emerged: quantum mechanics. Other laws operate at this level, and other concepts are used than those of the macrophysical world: the quantum particle has a dual nature, its behaviour being probabilistic, non-deterministic in the classical sense, subject to Heisenberg's principle. The bootstrap hypothesis in quantum mechanics, which is a principle of self-consistency, reveals that a particle is what it is because all other particles exist simultaneously, complexity being an essential feature of the world.

The essential idea that emerged from these findings was that nature seems to manifest itself paradoxically in the quantum world even at the fundamental level, which boosted the research of logicians, who came to construct this way new logical polyvalent systems. Within them, a special position is occupied by the logic of Stephane Lupasco, logic based on the idea of the existence of contradictory antagonistic energies, which favours the appearance of the T state, state of maximum antagonism that corresponds to a third value of truth (neither true nor false). This way, Lupascian logic turned out to be a trivalent one, in which the principle of the included third-party operates.

However, we believe that all this 'anti-positivist revolution' in the logical thinking of recent decades has failed to bring things to an end, i.e., getting rid of the 'straps' of the principle of non-contradiction and to assert the possibility and legitimacy of the principle of contradiction. So, on the one hand, at a purely 
Comşa Fr. Petre, Munteanu Costea (2020), The apodictic method and the dialogue between theology and science (I), The Journal of Philosophical Economics: Reflections on Economic and Social Issues, XIV (1-2), 136-176

formal level, Lupascian logic retains the principle of non-contradiction since contradiction and non-contradiction cannot be simultaneously actualized or simultaneously potentialized (virtualized). On the other hand, from the point of view of the logic of transdisciplinarity, the way in which the logic of the included third party is applied is consistent with the axiom of non-contradiction, provided the notions of 'true' and 'false' are broadened so that the rules of logical involvement refer to three terms (A, non-A and state $\mathrm{T}$ ) instead of two. In other words, accepting the existence of several levels of 'Reality', the principle of the excluded third party is no longer a consequence of the axiom of noncontradiction, but the principle and the axiom become independent entities; therefore, the axiom of non-contradiction may be valid without nullifying the principle of the included third party.

In contrast to the 'broken horizon' proposed by such approaches, this paper aims to make a modest contribution to bringing things to an end in breaking free from the ineffective constraints of the principle of non-contradiction as to finally arrive at the configuration of an antinomic logic based on the apodictic method as a 'grammar' of the dialogue between science and Orthodox theology. We aim to go further, based on the analyses and demonstrations developed in this sense by Pavel Florenski [25], whom contemporaries called a real 'Russian Leonardo da Vinci' or an 'Orthodox Pascal'.

Let us start with what we might call the fundamental problem of knowledge: how is reason possible in a world where everything is doomed to ephemerality and uncertainty and where 'the only sure thing is that nothing is certain and nothing is more miserable and arrogant than the man' [26]. In essence, we believe that the answer lies in recognizing the antinomic nature of reason.

Let us explain, knowledge is given in the form of a judgment, in other words as a synthesis between a specific subject $\mathrm{S}$ and a specific predicate $\mathrm{P}$ [27]. And, if any judgment is the synthesis of a duality, then why wouldn't another synthesis be possible, between the given subject $\mathrm{S}$ and another predicate $\mathrm{P}$ ? Then, why can't the given subject $\mathrm{S}$ not be related to P's negation, to non-P? It is clear, from here, that any judgment is contingent, that is it can be objected to in the form of another contradictory (or quite the contrary [28]) judgment. And even if up to some point in time and in a specific spatial context no such objection arose, it 
Comşa Fr. Petre, Munteanu Costea (2020), The apodictic method and the dialogue between theology and science (I), The Journal of Philosophical Economics: Reflections on Economic and Social Issues, XIV (1-2), 136-176

does not in any way guarantee the irrefutable nature of the judgment in question, in other time and elsewhere.

The above is reinforced by the daily experience that each of us has, namely, life is infinitely richer than the definitions that can be given by reason, and therefore, no formula can encompass the fullness of life. So, no formula can substitute life itself in its becoming /creation, in the edification of the new in every moment and everywhere. Therefore, always, and everywhere, the definitions of reason are and will be subject to objections. The objections to the formula are themselves formulas, counter-judgments, which result from aspects of life complementary to the given aspect, from aspects of the judgment that are contrary or even contradictory in relation to the given formula, subject to challenge.

It enables us to say that a rational formula can be above the attacks of life when and only when it absorbs the whole of life, with all its diversity and all its present and future contradictions. A rational formula can only be true when, so to speak, it sets out all the objections and answers them. So, the truth is a judgment that contains in itself all its rejections, or, in other words, the truth is a judgment that contradicts itself.

From a formal point of view, the unconditional character of truth consists even in the fact that it presupposes and accepts its negation in advance and answers the doubt regarding its authenticity, having in itself this doubt. The truth is true precisely because it is not afraid of any contestations; and it is not afraid because it itself speaks against itself more than any denial can say. But the truth combines this self-denial with an affirmative statement, which means that, for reason, the truth is a contradiction, and this contradiction becomes evident as soon as the truth receives a verbal formulation. Each of the contradictory sentences is contained in the judgment of truth, and therefore the presence of each is necessarily demonstrable with the same degree of conviction. Thesis and antithesis together form the expression of truth. In other words, the truth is an antinomy and cannot but be so. 
Comşa Fr. Petre, Munteanu Costea (2020), The apodictic method and the dialogue between theology and science (I), The Journal of Philosophical Economics: Reflections on Economic and Social Issues, XIV (1-2), 136-176

\section{Endnotes}

[1] The term 'paradox' is considered in many of the specialized works synonymous with that of 'antinomy' (concept introduced by Kant). However, for some authors, the terms are different: the paradox is when a sentence / judgment is self-contradictory, i.e., it can be true if it is false, and vice versa; while the antinomy expresses the contradiction between two mutually exclusive theses that can be logically demonstrated to the same extent. Further in our paper, we will consider that the two terms are interchangeable.

[2] Style figure consisting in the suppression of (copulative) conjunctions to give dynamism to the sentence.

[3] In the following paragraphs in this subsection we take the lines of analysis and argumentation developed in Berian (2010).

[4] Although Frege's influence on logical empiricism is obvious, it should be noted that Frege delimits himself from the empiricists.

[5] It is worth mentioning here that, more than a century ago, Leibnitz stated that the sentences of logic and mathematics are analytical, as confirmed by B. Russel in his book $A$ Critical Exposition of the Philosophy of Leibnitz (Allen \& Unwin, London, 1975): 'Regarding analytical sentences, Leibnitz argues that all sentences of logic, arithmetic and geometry are of this kind.'

[6] Frege sees the sentence as a whole (the separation in subject and predicate being irrelevant), characterized by the value of truth ('true' or 'false'). The content of the sentences can be abstracted, they acquire formal, abstract notations ('p', 'q', ...), the connection between the sentences being made through quantifiers ('and', 'or' etc.).

[7] It can be said that the distinction between notion and object is one of the guiding principles of the logic developed by Frege.

[8] To illustrate Frege's conception, consider, for example, four red objects: an apple, a flower, a shirt, and a book. Frege distinguishes between signals and characteristics: 'red' is the characteristic of all four red objects subsumed under the notion of 'red object', 'red' being only a signal for the notion of 'red object', but not its characteristic (the notion cannot be red). Characteristics can also be 
Comşa Fr. Petre, Munteanu Costea (2020), The apodictic method and the dialogue between theology and science (I), The Journal of Philosophical Economics: Reflections on Economic and Social Issues, XIV (1-2), 136-176

assigned to notions, but these are called second order characteristics as opposed to first order characteristics, which can only be attributed to objects, and which are signals for the notions to which these objects are subsumed. In the example above, the notion of 'red object' has the characteristic (of order 2) to which a number can be assigned. According to Frege, the number ('4' in our case) belongs to a third category, being defined as 'the sphere of the notion'.

It is observed that a first order characteristic cannot be assigned to a notion and no second order characteristic can be assigned to an object. Frege showed that if we do not distinguish between the properties of objects and notions, ordering them on different levels, there appear confusions in language. Thus, a hierarchy of characteristics is outlined in it, its non-observance leading to the appearance of semantic antinomies. Linking the above to the concept of function, Frege generalizes, admitting that the argument of a function can in turn be a function, not an object, distinguishing between first-order functions (which have as arguments objects) and second-order functions (which have as arguments first order functions).

[9] One of Aristotle's formulations of the principle of non-contradiction: 'It is impossible for two contradictory judgments to be true at the same time' (see Aristotle 1996).

[10] Paradox formulated by Eubulides of Miletus. If I say 'I lie' there are two possibilities: I tell the truth, so I'm lying, or I'm lying, so I'm telling the truth. There are two more well-known variants of it. One is that of the Cretan Epimenides 'liar', which states that 'All Cretans are liars', and the other one, more recent, 'This statement is false' written on a board generates an obvious paradox.

[11] In 1919, Russell formulated a popular equivalent of this paradox. The barber of a village shaves exactly those people who don't shave themselves. If the barber shaves himself, then he does not shave alone, and vice versa.

[12] Russell introduces the principle of the vicious circle. The vicious circle arises from the assumption that a collection of objects could contain an object that can only be defined with the help of the collection itself. Consequently, Russell states a principle to avoid this vicious circle: 'What a collection taken as a whole entails cannot be a member of the collection' (see B. Russell, Principia Mathematica, 
Comşa Fr. Petre, Munteanu Costea (2020), The apodictic method and the dialogue between theology and science (I), The Journal of Philosophical Economics: Reflections on Economic and Social Issues, XIV (1-2), 136-176

Vol. I, Cambridge, Cambridge University Press, 1910). In other words, no member of the collection can be defined by the collection to which it contributed as a member. (For example, the multitude of multitudes that do not include themselves cannot be defined, as it defines a new member (the multitude) with the help of the multitude to which it belongs (the multitudes that do not include themselves).

Russell expresses this idea using propositional functions. A propositional function $\Phi(\mathrm{x})$ contains a variable part, $\mathrm{x}$, and a determined part, $\Phi$, without any value of truth until the substitution or quantification of the variable part. For example, the expression ' $\mathrm{x}$ is green.', i.e., $\mathrm{x}$ has the property $\Phi$, 'green', is a propositional function, without truth value (just a 'wrapper' according to Russell's expression), if $\mathrm{x}$ is just an indeterminate variable. If $\mathrm{x}$ is replaced by the expression 'fir tree', the true sentence is obtained by substitution: 'the fir tree is green'. By quantification it also results either as a false sentence (' $\forall \mathrm{x} \Phi$ ( $\mathrm{x}$ )', that is ' $\mathrm{x}$ is always green'), or a true one (' $\exists \mathrm{x} \Phi(\mathrm{x})$ ', which means ' $\mathrm{x}$ is green sometimes').

In other words, the argument of a propositional function cannot be the function, or the class determined by the function. Therefore, the contradiction can be avoided if it is considered that, in the formalized writing of the paradox, the expressions:

' $\mathrm{x}(\mathrm{x})$ ' and 'imp(imp)'are meaningless. It is necessary, therefore, to make a limitation of the possible values of the argument of a propositional function, the allowed values forming a 'type'.

Russell proposes a system for ranking logical objects by type. These are:

- individuals, the lowest level, which are not properties - (type 0);

- properties of individuals, multitudes of individuals, predicates of individuals - (type 1);

- properties of the properties of individuals, multitudes of multitudes of individuals, predicates of predicates of individuals - (type 2) etc.

The hierarchy can be infinite. For example, let us consider the following case: individuals 'apple' and 'ball' (type 0); their properties as individuals: 'red' - for 'apple' and 'spherical' - for 'ball' (type 1); the properties of the properties of 
Comşa Fr. Petre, Munteanu Costea (2020), The apodictic method and the dialogue between theology and science (I), The Journal of Philosophical Economics: Reflections on Economic and Social Issues, XIV (1-2), 136-176

individuals: 'colour' and, respectively, 'geometric shape' (type 2). The expressions 'the apple is red' or 'the ball is spherical' make sense. So are the expressions: 'red is a colour' or 'spherical is a spatial property'. In all these expressions we observe that the argument of the function belongs to a type inferior to the one characteristic of the function. If we try to assign a function to an argument that belongs to a type superior to the one characteristic of the function, we obtain meaningless expressions, such as: 'spatial property is spherical' or 'red is apple'. The same applies if the argument and function belong to the same type: 'red is spherical', or 'colour is a spatial property'. It follows that Russell's rule is that a function of type $\mathrm{n}$ must contain, at least, one argument of the order $\mathrm{n}-1$ and not contain any argument of order $n$, or greater than $n$.

[13] Brower's logical-philosophical doctrine is known as intuitionism.

[14] As it will be seen further in our study, Brower is not the only one who 'attacks' the universal validity of the excluded third-party principle.

[15] Brower's axiom: the absurdity of absurdity does not imply truth; but the truth implies the absurdity of absurdity.

[16] In Cantor's, respectively Russell's paradoxes, notions appear such as 'infinite innumerable multitudes' (for example the multitude of real numbers) which have a 'transfinite cardinal number' (the cardinal of the multitude of real numbers, which is greater than the largest real number). As the intuitive support has lacks in relation to the above-mentioned notions, Brower considers these notions meaningless. More meaningless is the multitude of all the innumerable infinite multitudes. Mathematics being independent of logic, it cannot be built on elements related to multitude theory. Thus, given that the object of the discussion related to paradoxes disappears, the paradox itself no longer exists.

[17] It is worth mentioning, in the context, which are the three main ideas belonging to quantum mechanics that generated the extension of logic by creating trivalent logical systems (cf. Anton Dumitriu): (1) Heisenberg's principle of indeterminacy; (2) Bohr's principle of complementarity; and (3) the probabilistic nature of the laws of quantum mechanics. 
Comşa Fr. Petre, Munteanu Costea (2020), The apodictic method and the dialogue between theology and science (I), The Journal of Philosophical Economics: Reflections on Economic and Social Issues, XIV (1-2), 136-176

[18] As Lukasiewicz comments (cf. Anton Dumitriu), it seems that Aristotle also admitted the existence of a situation where the principle of the excluded third is not valid (see Aristotle 2005): acts achievable in the future that are subject to the free will of man are called future contingents. This is the Aristotle's statement that leads to this conclusion: it is necessary to have a battle at sea tomorrow, or not at all; but it is not necessary for it to take place tomorrow, nor is it necessary for it not to take place '.

[19] The Romanian physicist Basarab Nicolescu considers that most quantum logics have changed the axiom of non-contradiction and not the principle of the excluded third party; the two postulates were, for the logicians of the time, inseparable and equivalent, since there was, for them, only one level of Reality. For the quoted author, only a model based on the existence of several levels of Reality will be able to separate the axiom of non-contradiction from that of the included third party.

[20] The reasoning developed by Février was the following (see P. Fevrier, 'Les relation d'incertitude d'Heisenbeg et la logique', Travaux de IX-e Congrès International de Philosophie, VI, Paris, apud Berian 2010, p.57): if we measure, simultaneously, the $\mathrm{x}$ coordinate and the $\mathrm{p}$ impulse of a micro-particle, we obtain the approximate values (due to the Heisenberg principle) 0x, respectively 0p. Let us consider the sentences:

$$
\begin{aligned}
& a=x \text { has the value } 0 x, \\
& b=p \text { has the value } 0 p .
\end{aligned}
$$

The conjunction a \& b cannot be true, because it would assume that both a and $\mathrm{b}$ are simultaneously true no matter how small $0 \mathrm{x}$ and $0 \mathrm{p}$ are, thus violating Heisenberg's principle. To solve the problem, Février defines a special logical product, called 'incomposable', and an additional logical value, in addition to 'true' ('the possible realized') and 'false' ('the possible unrealized'): 'the unrealizable possible', which Février calls 'absurd'. According to Heisenberg's relation, the incompatible product between a and $b$ cannot take values less than Planck's constant, but in this case the value of 'absurd' truth can be associated with it, as the values below $\mathrm{h}$ of this product are unachievable. According to A. Dumitriu's evaluation, this way the contradiction in Février's system is eliminated. 
Comşa Fr. Petre, Munteanu Costea (2020), The apodictic method and the dialogue between theology and science (I), The Journal of Philosophical Economics: Reflections on Economic and Social Issues, XIV (1-2), 136-176

[21] Inspired by the dualism introduced by de Broglie in quantum mechanics, Lupasco postulates that every phenomenon, element, or logical event e must be associated with an anti-phenomenon, anti-element, or logical anti-event $\bar{e}$. The actualization (with the meaning: coming into existence) of e always and necessarily determines the potentialization (with the meaning: passing into virtuality) of $\bar{e}$, and vice versa, without any of them being able to be absolutely virtualized, thus disappearing by the absolute actualization of the other. When $\mathrm{e}$ and $\overline{\mathrm{e}}$ are at the same level of actualization, or potentialization (moving from actual to virtual or vice versa), they will not be reduced to 0 (as in classical logic), but will be reduced to the state $\mathrm{T}$, in which it is considered that both e and $\overline{\mathrm{e}}$ are, relative to each other, semiactual and semipotential at the same time. The classical postulate of non-contradiction and identity, formally expressed by $p \supset p$ (i.e., the sentence $p$ implies $p$ ), is replaced by the fundamental postulate of the dynamic logic of contradiction:

$$
\begin{aligned}
& \text { ea } \supset \bar{e} \mathrm{p}, \overline{\mathrm{e}} \mathrm{a} \supset \mathrm{ep}, \mathrm{eT} \supset \overline{\mathrm{e} T} \\
& \text { ep } \supset \text { ēa , ēp } \supset \text { ea , èT } \supset \text { eT }
\end{aligned}
$$

Indices $\mathrm{A}, \mathrm{P}, \mathrm{T}$, indicate the three states: actualization, potentialization, respectively state T. Row (1) expresses the relationships stated above: if e is actualized, then $\overline{\mathrm{e}}$ is potentialized (virtualized); if $\overline{\mathrm{e}}$ is actualized, then e will be potentialized (virtualized); finally, if e is neither fully potential nor fully actual, then $\bar{e}$ is neither fully-actual nor fully-potential. Reading relation (2) is similar.

The value table of Lupascian logic is represented (see below) in comparison with the value table of bivalent classical logic (the following symbols were used: $\mathrm{A}$ - actualization, $\mathrm{P}$ - potentialization, $\mathrm{T}$ - state $\mathrm{T}$, for Lupascian logic; as well as $\mathrm{T}$ - true, $\mathrm{F}$ - false, for classical logic):

Value table of Lupascian logic:

$\begin{array}{lllll}\mathrm{e} & \Rightarrow \mathrm{A} & \mathrm{T} & \mathrm{P} \\ \overline{\mathrm{e}} & \Rightarrow \mathrm{P} & \mathrm{T} & \mathrm{A}\end{array}$

Value table for classical logic:




Comşa Fr. Petre, Munteanu Costea (2020), The apodictic method and the dialogue between theology and science (I), The Journal of Philosophical Economics: Reflections on Economic and Social Issues, XIV (1-2), 136-176

By this, any logical phenomenon is through its dual and contradictory nature a contradictory structural and functional dynamism. Thus, we arrive at the 'postulate of the logic of energy', i.e., the principle of antagonism: a specific dynamism, an energy, necessarily implies the existence of a second energy, a second antagonistic dynamism, to which it allows actualization by its potentialization and which, conversely, is potentialized (virtualized) by the actualization of the first. Therefore, it is not possible to have a solitary dynamism or, in other words, 'if there is an energy, there is necessarily a negative energy'.

Turning again our attention to the two contradictory events marked with e and $\overline{\mathrm{e}}$ as one of them is actualized and the other is virtualized, the non-contradiction is actualized more and more, diminishing in this way the contradiction. However, non-contradiction can never be completely actualized, in an absolute way, due to the residual contradiction, which cannot be null.

In other words, no logical event can be absolutely non-contradictory. If, instead, e and $\overline{\mathrm{e}}$ are simultaneously semi-actual and semi-potential (state $\mathrm{T}$ ), the actualization of the contradiction is maximum. Therefore, the state $\mathrm{T}$ corresponds to a maximum antagonism, a maximum energy density, or, speaking in informational terms, corresponds to a maximum organization.

Contradiction and non-contradiction, respectively, cannot be absolute; the contradiction is relatively actualized when it is generated by state $\mathrm{T}$, and is relatively virtualized when it is rejected by the relative non-contradiction of states $\mathrm{A}$ and $\mathrm{P}$. It is observed that the generation of contradiction occurs by mutual inhibition of two phenomena, being prevented the actualization of one due to potentialization of the other.

[22] Although the association of the wave with the idea of continuity and the corpuscle with that of discontinuity can be made at some level, Lupasco points out that both the corpuscle and the wave each contain the continuousdiscontinuous duality.

[23] Pauli's principle postulates that there is no more than one fermion (particle with semi-whole spin, such as the electron or proton) in a quantum state characterized by the same quantum numbers, thus forcing fermions to differentiate, which is obviously a tendency to heterogenize. The principle is not valid for bosons (whole spin particles, such as the photon). 
Comşa Fr. Petre, Munteanu Costea (2020), The apodictic method and the dialogue between theology and science (I), The Journal of Philosophical Economics: Reflections on Economic and Social Issues, XIV (1-2), 136-176

[24] The second principle of thermodynamics states that physical systems evolve irreversibly in the sense of transformation higher forms of energy (mechanical, chemical, electrical) into the lower form of heat, which is an expression of uniformity, homogenization. The entropy increases during this process, which translates into an increasing dose of disorder in the system.

[25] Pavel A. Florenski (1882-1937) is, we believe, one of the most universal brilliant and profound spirits of the twentieth century. Mathematician, physicist, engineer, philosopher and historian of philosophy, philologist, polyglot, aesthetician and theorist of arts, language and culture theologian and Orthodox priest, martyr of the Eastern Church, Florenski creatively merged in his person and reflection, in an organic, living, and concrete synthesis, unique and stimulating - both for contemporaries and for us, today - religion and the exact sciences, worship and culture, Church and the world, revelation and reason. In this section of our study, we will take over the ideas, argumentation and demonstrations developed in Florenski 1999, pp.96-110.

[26] Plinius the Elder, apud Ioan Ică jr., 'Introductory study' to Florenski, idem, p. xxxviii.

[27] Neither the analytical judgment, nor even identity are excluded because the subject and the predicate in them are different in a sense. So, we must first distinguish between them, to bring them together later. (As we have already had the occasion to show in our study, following Kantian terminology, in all the judgments in which the relation between a subject and a predicate is thought we consider only the affirmative judgments, for the negative ones are then easy to apply - this report is possible in two ways: Either the predicate B belongs to the subject A as something that is contained - implicitly - in this concept, or B is completely outside the concept A, although it is related to it. In the first case the judgment is called analytical, in the other, synthetic. Affirmative analytical judgments are therefore those in which the connection of the predicate with the subject is thought through identity, and those, in which this connection is thought without identity, must be called synthetic judgments).

[28] Unlike two contradictory things (which destroy each other ipso facto), two opposite things can coexist independently of each other; they can be the attributes of the same subject (humanity can be made up of black and white 
Comşa Fr. Petre, Munteanu Costea (2020), The apodictic method and the dialogue between theology and science (I), The Journal of Philosophical Economics: Reflections on Economic and Social Issues, XIV (1-2), 136-176

people), just as they can be the subjects of the same attribute (blacks and whites can have the same culture, intelligence, etc.) (the example is taken from Stephane Lupasco). Still the pre-Socratics (Heraclitus, Anaxagoras, Empedocles, etc.) conceived the universe according to the opposites. As for the contrary, as opposed to contradiction, it leaves intact the existence and reality of the opposites that compose it: in the sense that they are independent and separated from each other; in this case the separation of opposites means precisely the lack of connection between them - how, instead, it happens in the case of the contradiction where there is a connection between opposites -, a connection which is manifested there by the fact that the existence and identity of each opposite term consists in denying the existence and identity of the other term.

\section{References}

Aristotle (1961), Organon (Organon), Vol. III, Bucharest: Scientific Publishing House.

Aristotle (1996), Metafizica (Metaphysics), Bucharest: IRI Publishing House.

Aristotle (2005), Despre interpretare (On Interpretation), Bucharest: Humanitas Publishing House.

Berian, Sergiu (2010), 'Cercetări privind potențialul transdisciplinar al mecatronicii', doctoral thesis, Technical University of Cluj-Napoca, Faculty of Mechanics.

Botezatu, Petre (1973), Semiotică și negare, Iaşi: Junimea Publishing House.

Botezatu, Petre (1983), Constituirea logicității, Bucharest: Scientific and Encyclopaedic Publishing House.

Breck, John (2006), 'Prefață', in Răzvan Andrei Ionescu and Adrian Nicolae Lemeni, Teologie ortodoxă și știință, Bucharest: Publishing House of the Biblical and Mission Institute of the Romanian Orthodox Church.

Dumitriu, Anton (1941), Logica lui Hilbert, Bucuresti: Revista Fundatiilor Regale.

Dumitriu, Anton (1968), Mecanismul logic al matematicii, Bucharest: Romanian Academy Publishing House. 
Comşa Fr. Petre, Munteanu Costea (2020), The apodictic method and the dialogue between theology and science (I), The Journal of Philosophical Economics: Reflections on Economic and Social Issues, XIV (1-2), 136-176

Dumitriu, Anton (1969), Istoria logicii, Bucharest: Didactic and Pedagogical Publishing House.

Dumitriu, Anton (1986), Eseuri, Bucharest: Eminescu Publishing House.

Enescu, Gheorghe (1967), Logică și adevăr, Bucharest: Politics Publishing House.

Enescu, Gheorghe (1973), Filosofie și logică, Bucharest: Scientific Publishing House.

Enescu, Gheorghe (2003), Paradoxuri, sofisme, aporii, Bucharest: Technical Publishing House.

Evdokimov, Paul (1996), Ortodoxia, Bucharest: EIBMBOR.

Florenski, Pavel (1999), Stâlpul și Temelia Adevărului. Incercare de teodicee ortodoxă în douăsprezece scrisori, Iași: Polirom.

Frege, Gottlob (1977), Scrieri logico-filosofice, vol. I, Bucharest: Scientific and Encyclopaedic Publishing House.

Kant, Immanuel (1994), Critica rațiunii pure, Bucharest: IRI Publishing House.

Korner, Stephan (1965), Introducere in filosofia matematicii, Bucharest: Scientific Publishing House.

Lupasco, Stéphane (1940), L'éxperience microphysique et la pensée humaine, Bucharest: 'King Carol II' Foundation for Literature and Art.

Lupasco, Stéphane (1970), La tragédie de l'énergie, Paris: Casterman.

Lupasco, Stéphane (1982), Logica dinamică a contradictoriului, Bucharest: Politics Publishing House.

Mihalache, Adrian Sorin (2016), Lumina Celui Nevăzut, vol. I, Bucharest: Basilica Publishing House.

Nesteruk, Alexei ([2008] 2009), Universul în comuniune. Către o sinteză neopatristică a teologiei șiștiinței, Romanian translation by Silviu-Mihai Chirilă, Bucharest: Curtea Veche Publishing House.

Nicolescu, Basarab (1999), Transdiciplinaritatea, Manifest, Iași: Polirom.

Nicolescu, Basarab (2002), Noi, particula și lumea, Iași: Polirom. 
Comşa Fr. Petre, Munteanu Costea (2020), The apodictic method and the dialogue between theology and science (I), The Journal of Philosophical Economics: Reflections on Economic and Social Issues, XIV (1-2), 136-176

Nicolescu, Basarab (2007), Noi, particula și lumea, Iași: Editura Junimea.

Nicolescu, Basarab, Marta Stavinschi (ed.) (2003), Science and Religion. Antagonism or Complementarity?, Bucharest: XXI Publishing House.

Nicolescu, Basarab, Marta Stavinschi (ed.) (2006), Science and Orthodoxy, a Necessary Dialogue, Bucharest: Curtea Veche Publishing House.

Russel, Bertrand (1975), A Critical Exposition of the Philosophy of Leibnitz, London: Allen \& Unwin.

Saint Basil the Great (1986), Omilii la Hexaemeron, Church Fathers and Writers Collection, vol.17, Bucharest: EIBMBOR.

Saint Gregory Palamas (2013), Opere complete, vol. II / B, Bucharest: Gândul Aprins Publishing House.

Saint Gregory Palamas (2015), Opere complete III - Cuvinte în apărarea celor ce se liniștesc în chip sfânt, Bucharest: Gândul aprins Publishing House.

Solomon, Marcus (1984), Paradoxul, Bucharest: Albatros Publishing House.

Stăniloae, Dumitru (1993), Ascetică și mistică ortodoxă, vol.1, Alba Iulia: Deisis Publishing House.

Stăniloae, Dumitru (1993), Viața și spiritualitatea Sfântului Grigorie Palama, 2nd Edition. Bucharest: Sophia Publishing House.

Sturzu, Constantin (2009), 'Caracterul antinomic al dogmaticii ortodoxe', in Dialogul dintre teologie și filosofie, 2nd edition, Bucharest: Basilica Publishing House.

Tarski, Alfred (1956), Logic, Semantics, Metamathematics, Oxford: Clarendon Press.

Fr. Petre Comșa, Ph.D, is Senior Lecturer, Faculty of Theology, Valahia University, Târgoviște (Romania) (comsa.petre@gmail.com).

Costea Munteanu, Ph.D, is retired Professor with the Bucharest University of Economic Studies, Bucharest (Romania) and founding member of the Romanian Institute for Free Enterprise, Bucharest (costea_munteanu@yahoo.com). 